\title{
Generation of $\alpha$-1,3-galactosyltransferase knocked-out transgenic cloned pigs with knocked-in five human genes
}

\author{
Dae-Jin Kwon • Dong-Hwan Kim • In-Sul Hwang • Dong-Ern Kim • Hyung-Joo Kim • \\ Jang-Seong Kim $\cdot$ Kichoon Lee $\cdot$ Gi-Sun Im $\cdot$ Jeong-Woong Lee $\cdot$ Seongsoo Hwang
}

Received: 1 March 2016/Accepted: 17 August 2016/Published online: 23 August 2016

(C) The Author(s) 2016. This article is published with open access at Springerlink.com

\begin{abstract}
Recent progress in genetic manipulation of pigs designated for xenotransplantation ha6s shown considerable promise on xenograft survival in primates. However, genetic modification of multiple genes in donor pigs by knock-out and knock-in technologies, aiming to enhance immunological tolerance against transplanted organs in the recipients, has not been evaluated for health issues of donor pigs. We produced transgenic Massachusetts General Hospital piglets by knocking-out the $\alpha$-1,3-galactosyltransferase (GT) gene and by simultaneously knocking-in an expression cassette containing five different human genes including, DAF, CD39, TFPI, C1 inhibitor (C1-INH), and TNFAIP3 (A20) [GT $\left.^{-(\mathrm{DAF} / \mathrm{CD} 39 / \mathrm{TFPI} / \mathrm{C} 1-\mathrm{INH} / \mathrm{TNFAIP3}) /+}\right]$
\end{abstract}

Dae-Jin Kwon, Dong-Hwan Kim and In-Sul Hwang have contributed equally to this work.

Electronic supplementary material The online version of this article (doi:10.1007/s11248-016-9979-8) contains supplementary material, which is available to authorized users.

D.-J. Kwon · I.-S. Hwang · G.-S. Im · S. Hwang ( $\bigotimes)$

National Institute of Animal Science, Rural Development

Administration, Wanju, Jeollabuk-do 55365,

Republic of Korea

e-mail: hwangss@korea.kr

D.-H. Kim · D.-E. Kim · H.-J. Kim •

J.-S. Kim · J.-W. Lee $(\bowtie)$

Biotherapeutics Translational Research Center, Korea

Research Institute of Bioscience and Biotechnology,

Daejeon 34141, Republic of Korea

e-mail: jwlee@kribb.re.kr that are connected by $2 \mathrm{~A}$ peptide cleavage sequences to release individual proteins from a single translational product. All five individual protein products were successfully produced as determined by western blotting of umbilical cords from the newborn transgenic pigs. Although gross observation and histological examination revealed no significant pathological abnormality in transgenic piglets, hematological examination found that the transgenic piglets had abnormally low numbers of platelets and WBCs, including neutrophils, eosinophils, basophils, and lymphocytes. However, transgenic piglets had similar numbers of RBC and values of parameters related to RBC compared to the control littermate piglets. These data suggest that transgenic expression of those human genes in pigs impaired hematopoiesis except for erythropoiesis. In conclusion, our data suggest that transgenic expression of up to five different genes can be efficiently achieved and provide the basis for determining optimal dosages of transgene expression and combinations of the

\section{D.-H. Kim · J.-W. Lee}

Department of Functional Genomics, University of Science and Technology, Daejeon 34113,

Republic of Korea

K. Lee

Department of Animal Sciences, The Ohio State University, Columbus, OH 43210, USA 
transgenes to warrant production of transgenic donor pigs without health issues.

Keywords Multi-transgenic pigs ·

Xenotransplantation - Immune rejection · Leucopenia · Thrombocytopenia

\section{Introduction}

Xenotransplantation of organs from a readily available animal species, such as the pig, into humans has been considered as a potential solution to the critical shortage of organs from deceased human donors for transplantation (Yamada et al. 2005; Griesemer et al. 2009). However, the immune rejection response due to species disparity between pigs and primates is the major hurdle in successful xenograft transplantation. A great amount of effort has been applied to prolong survival periods of transplanted xenografts, including the deletion of galactose- $\alpha-1,3$-galactose antigens ( $\alpha$ Gal) by knockout of the $\alpha$-1,3-galactosyltransferase (GT KO) gene (Lai 2002) and simultaneous inhibition of human complement activation by the introduction of human complement-regulatory genes, such as CD46, CD55 (decay accelerating factor; DAF) (Lee et al. 2011), and CD59, in the pigs used for xenotransplantation (Lambrigts et al. 1998; McGregor et al. 2004). The classical pathway complementregulatory protein $\mathrm{C} 1$ inhibitor $(\mathrm{C} 1-\mathrm{INH})$ has also been reported to be able to prevent complementmediated activation of xenogeneic endothelial cells (Dalmasso and Platt 1993; Wheeler et al. 2012). Due to the presence of non-Gal antibodies and molecular incompatibilities between coagulation systems of primates and pigs, thrombotic microangiopathy has often developed in the vascularized graft tissues. Moreover, inflammatory responses against pig organs may evoke some acute vascular rejection. However, these problems may be overcome by the introduction of human coagulation-regulatory genes, such as thrombomodulin and tissue factor pathway inhibitor (TFPI) (Lee et al. 2011), or human anti-inflammatory genes, such as hemeoxygenase-1 and CD39 (Wheeler et al. 2012) and/or tumor necrosis factor- $\alpha$ induced protein 3 (TNFAIP3; A20) (Daniel et al. 2004; Oropeza et al. 2009), respectively. As a result, significant progress has been made in that cardiac xenograft from GT KO pigs with human complement regulatory protein (hCD46, membrane cofactor protein) and human thrombomodulin molecules to baboons had survived for over 900 days (Mohiuddin et al. 2015). Also, an efficacy of renal xenotransplantation has been established with survival and organ functionality extending over 227 days with GT KO/ CD55 transgenic pig-to-macaque (Higginbotham et al. 2015).

Although the expression of these human genes in the pigs for xeno-organ sources has revealed some beneficial effects in the success of xenotransplantation, it is not clear and remains to be determined what combination of genes would be better to develop a state of immunological tolerance against transplanted organs in the recipients. To achieve this goal, genetic introduction of multiple genes into pigs would be required. Thus, there has been an urgent need for the development of an efficient strategy for the introduction of multiple human genes in those pigs.

In the present study, we attempted to produce a transgenic piglet with GT KO and simultaneously expressing multiple transgenes, including human DAF, hCD39, hTFPI, hC1-INH, and hTNFAIP3. Here, we report technical advantages of this approach to generate the $\mathrm{MGH} \mathrm{GT}^{- \text {(DAF/CD39/TFPI/C1-INH/TNFAIP3)/+ }}$ piglets as well as some health issues of these transgenic pigs.

\section{Materials and methods}

General information

All chemicals were purchased from Sigma-Aldrich Corp. (St. Louis, MO, USA) and all restriction enzymes were from New England Biolabs (Ipswich, MA, USA) unless otherwise stated. The study protocol and standard operating procedures for the treatments of the pigs used in the present study were reviewed and approved by the Institutional Animal Care and Use Committee of the National Institute of Animal Science, Rural Development Administration of Korea (approval number: 2012-D-001, NIAS2015-671).

Construction of a zinc finger nuclease (ZFN) vector

A pair of ZFN vectors was constructed for targeting exon 9 of the GT gene. The coding sequence of DNA 
binding domain, used in the previous study (Hauschild et al. 2011), was synthesized (Bioneer Inc., Daejeon, Korea) and inserted into a ZFN expression vector, pST1374, in the BamHI and XbaI sites to make a $\mathrm{PaGE9L/R}$ vector. Cloned DNA sequences were confirmed by DNA sequencing analysis (Genotech, Daejeon, Korea).

Polymerase chain reaction and gene cloning

Total RNA was isolated from human umbilical vein endothelial cells using TRIZOL reagent (Life Technologies, Carlsbad, CA, USA) and used for reverse transcription by SuperScript III first-strand synthesis system (Invitrogen, Life Technologies, Carlsbad, CA, USA) according to the manufacturer's instruction. Complementary DNAs coding for human DAF, CD39, TFPI, C1-INH, or TNFAIP3 were amplified by PCR with $p f u$ DNA polymerase (Enzynomics, Daejeon, Korea) using specific primer sets (Suppl. Table 1) and human cDNAs as the template. PCR conditions were as follows: hDAF, initial denaturation at $95{ }^{\circ} \mathrm{C}$ for $5 \mathrm{~min} ; 35$ cycles of $94{ }^{\circ} \mathrm{C}$ for $30 \mathrm{~s}, 65^{\circ} \mathrm{C}$ for $30 \mathrm{~s}$, and $72{ }^{\circ} \mathrm{C}$ for $2 \mathrm{~min}$; followed by a final extension at $72{ }^{\circ} \mathrm{C}$ for $5 \mathrm{~min}$; hCD39, initial denaturation at $95{ }^{\circ} \mathrm{C}$ for $5 \mathrm{~min} ; 35$ cycles of $94{ }^{\circ} \mathrm{C}$ for $30 \mathrm{~s}$, $64{ }^{\circ} \mathrm{C}$ for $30 \mathrm{~s}$, and $72{ }^{\circ} \mathrm{C}$ for $2 \mathrm{~min}$; followed by a final extension at $72{ }^{\circ} \mathrm{C}$ for $5 \mathrm{~min}$; hTFPI, initial denaturation at $95{ }^{\circ} \mathrm{C}$ for $5 \mathrm{~min} ; 35$ cycles of $94{ }^{\circ} \mathrm{C}$ for $30 \mathrm{~s}, 62{ }^{\circ} \mathrm{C}$ for $30 \mathrm{~s}$, and $72{ }^{\circ} \mathrm{C}$ for $1 \mathrm{~min}$; followed by a final extension at $72{ }^{\circ} \mathrm{C}$ for $5 \mathrm{~min}$; hC1-INH, initial denaturation at $95{ }^{\circ} \mathrm{C}$ for $5 \mathrm{~min} ; 35$ cycles of $94{ }^{\circ} \mathrm{C}$ for $30 \mathrm{~s}, 64{ }^{\circ} \mathrm{C}$ for $30 \mathrm{~s}$, and $72{ }^{\circ} \mathrm{C}$ for $2 \mathrm{~min}$; followed by a final extension at $72{ }^{\circ} \mathrm{C}$ for $5 \mathrm{~min}$; hTNFAIP3, initial denaturation at $95{ }^{\circ} \mathrm{C}$ for $5 \mathrm{~min} ; 35$ cycles of $94{ }^{\circ} \mathrm{C}$ for $30 \mathrm{~s}, 64{ }^{\circ} \mathrm{C}$ for $30 \mathrm{~s}$, and $72{ }^{\circ} \mathrm{C}$ for $3 \mathrm{~min}$; followed by a final extension at $72{ }^{\circ} \mathrm{C}$ for $5 \mathrm{~min}$. Amplified DNA fragments were cloned into pGEM-easy TA cloning vector (Promega, Madison, WI, USA), and all cloned DNA fragments were confirmed by DNA sequencing analysis (Genotech).

\section{Construction of the pBS-2A5 vector}

Multiple 'self cleaving' 2A peptide sequences (Higginbotham et al. 2015), including P2A, T2A, E2A, or $\mathrm{F} 2 \mathrm{~A}$, were synthesized (Bioneer Inc.) and then inserted into the SacII and XhoI restriction enzyme sites of the pBluescript II KS (Addgene, Cambridge,
MA, USA) plasmid to make a pBS-2A vector. Porcine intercellular adhesion molecule 2 (ICAM2) promoter sequences were amplified by PCR with $p f u$ DNA polymerase (Enzynomics) and a specific primer set (Suppl. Table 1) using porcine genomic DNA as the template. PCR was performed under the following cycles: initial denaturation at $95{ }^{\circ} \mathrm{C}$ for $5 \mathrm{~min} ; 35$ cycles of $94{ }^{\circ} \mathrm{C}$ for $30 \mathrm{~s}, 66{ }^{\circ} \mathrm{C}$ for $30 \mathrm{~s}$, and $72{ }^{\circ} \mathrm{C}$ for $1 \mathrm{~min}$; followed by a final extension at $72{ }^{\circ} \mathrm{C}$ for $5 \mathrm{~min}$. The PCR product was inserted into pGEM-easy TA cloning vector to make pTA-ICAM2. The pTAICAM 2 vector was then cut by XhoI and SalI, and the digested DNA fragment was subcloned into the corresponding sites of the pBS-2A vector. Next, five human genes were digested with the following restriction enzymes (DAF, EcoRV and AvrII; CD39, SnaBI and SpeI; TFPI, SmaI and AvrII; C1-INH, StuI and NheII, and hTNFAIP3, NruI and SalI, respectively). The digested DNA fragments were subcloned into pBS-2A vector to make a pBS-ICAM2-2A5 vector. Construction of the vector was confirmed by digestion patterns with the following restriction enzymes: $X b a \mathrm{I}, S t u \mathrm{I}$, NheI, HindII, and BamHI. All cloned DNA sequences were confirmed by DNA sequencing analysis (Genotech).

Construction of the pLNDT-2A5-Gal expression vector

Genomic DNA from the Massachusetts General Hospital minipig (MGH minipig) was isolated using a genomic DNA extraction kit (Qiagen, Valencia, CA, USA) according to the manufacturer's protocol. $1 \mathrm{~kb}$ of $5^{\prime} \alpha$-Gal and $1.1 \mathrm{~kb}$ of $3^{\prime} \alpha$-Gal fragments were amplified by PCR with $p f u$ DNA polymerase (Enzynomics) using specific primer sets (Suppl. Table 1) and porcine genomic DNA as the template. The PCR cycles were as follows: initial denaturation at $95{ }^{\circ} \mathrm{C}$ for $5 \mathrm{~min} ; 35$ cycles of $94{ }^{\circ} \mathrm{C}$ for $30 \mathrm{~s}, 62{ }^{\circ} \mathrm{C}$ for $30 \mathrm{~s}$ and $72{ }^{\circ} \mathrm{C}$ for $1 \mathrm{~min}$; followed by a final extension at $72{ }^{\circ} \mathrm{C}$ for $5 \mathrm{~min}$. The PCR products were inserted into a pGEM-easy TA cloning vector to make pTA- $5^{\prime} \alpha-$ Gal and pTA- $3^{\prime} \alpha-\mathrm{Gal}$, respectively. The pTA- $5^{\prime} \alpha-\mathrm{Gal}$ and pTA-3 $3^{\prime} \alpha$-Gal vectors were digested with NotI/ XhoI or SalI/AscI restriction enzymes, respectively, and were subsequently inserted into the predigested pLNDT vector, which contains neomycin as a positive selection marker and diphtheria toxin $\mathrm{A}$ as a negative selection marker, to make a $\alpha$-Gal targeting vector, 
pLNDT-Gal. Finally, pBS-2A5 vector was digested with $X h o I$ and $P a c I$ restriction enzymes, and the digested DNA fragment was subcloned into the corresponding restriction sites of pLNDT-Gal to make a pLNDT-2A5-Gal vector (Fig. 1a). All cloned DNA sequences were confirmed by DNA sequencing analysis (Genotech).

Confirmation of expression of multiple human genes in pig cell lines

Before establishment of cell lines, the constructed ICAM2-2A5 vector was transfected into porcine aortic endothelial cells (PAECs) to verify whether the multiple human genes are expressed well in pig cells. To confirm the expression of each transgene, after the vector transfection, total RNA was isolated using TRIZOL reagent, according to the manufacturer's protocol, and was used for cDNA synthesis. PCR was performed using a primer set for each transgene (Suppl. Table 1) and cDNA as the template. The PCR cycle was as follows: initial denaturation at $95{ }^{\circ} \mathrm{C}$ for $5 \mathrm{~min}$; 22-36 cycles of $94{ }^{\circ} \mathrm{C}$ for $30 \mathrm{~s}$, the optimized annealing temperature for $30 \mathrm{~s}$, and $72{ }^{\circ} \mathrm{C}$ for $30 \mathrm{~s}$; followed by a final extension at $72{ }^{\circ} \mathrm{C}$ for $5 \mathrm{~min}$.
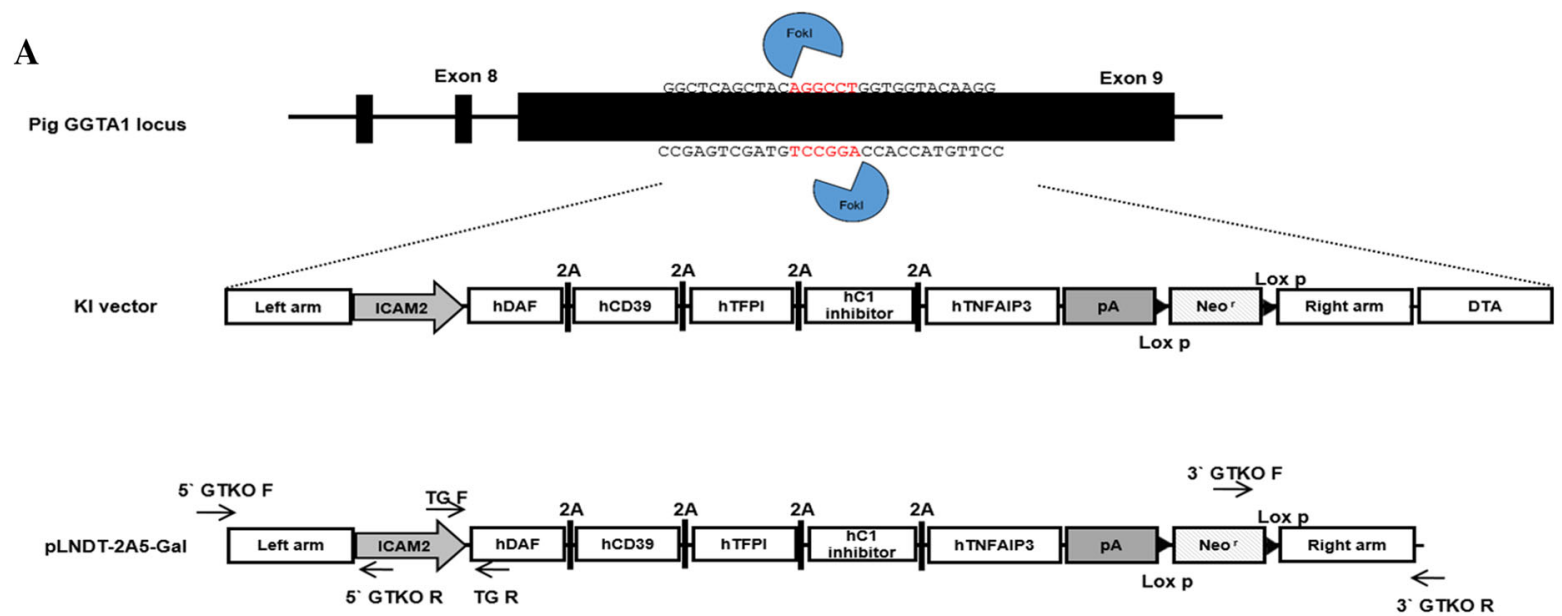

B

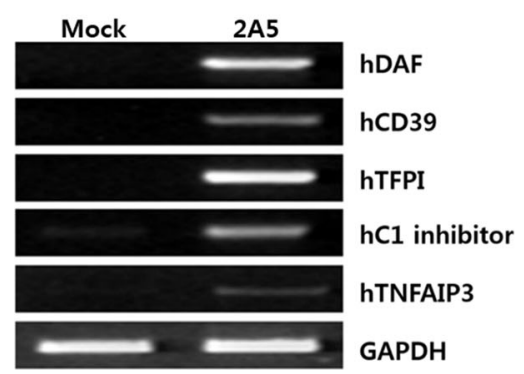

Fig. 1 Construction of multiple gene expression vector and identification of GGTA1 (GT) KO/multiple gene KI cell lines. a Schematic of a ZFN-based KI process. The KI vector pLNDT2A5-Gal has an expression unit for multiple genes with $5^{\prime}$ and $3^{\prime}$ $\alpha$-gal homology arms at its both end. In the bottom of this figure, the structure of working pLNDT-2A5Gal vector is shown. Primers used for identification of KI cell clones are shown above and below the constructs. b Confirmation of the multiple genes in porcine aortic endothelial cells (PAECs) by RT-PCR. Established the ICAM2-2A5 vector which is the multiple gene expression vector connected by $2 \mathrm{~A}$ was transfected into PAECs

C

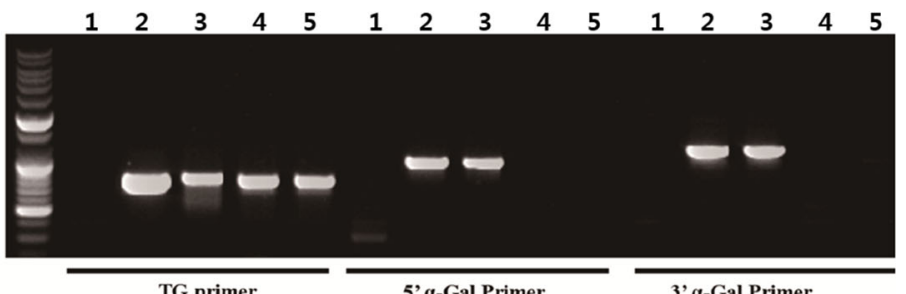

TG primer

5' $\alpha$-Gal Primer

3' $\alpha$-Gal Primer

and verified expression of the multiple genes by $2 \mathrm{~A}$ system before establishment of cell lines. NC: normal PAECs; 2A5: PAECs transfected ICAM2-2A5 vector. c Genotyping of selected cell lines. Targeting vector was transfected into ear fibroblasts from MGH minipigs (mpEF). Four cell lines were established and confirmed by 3 of specific primer sets: $0.8 \mathrm{~kb}$ of TG primer sets; $1 \mathrm{~kb}$ of $5^{\prime}$ a-Gal primer sets; $1.1 \mathrm{~kb}$ of $3^{\prime}$ a-gal primer stets. Among the four cell lines, only two of them were confirmed as transgenic cell lines. 1 normal pig genomic DNA; \#2 and 3 transgenic and Knock-in cells; \#4 and 5 transgenic cell lines 
Construction of knock-in cell line

Ear fibroblasts obtained from the MGH minipigs (mpEF) were cultured in Dulbecco's modified Eagle's medium (WelGene, Gyeongsan-si, Korea) containing $20 \%$ fetal bovine serum, $1 \mathrm{mM}$ of non-essential amino acid (GIBCO), $1 \mathrm{mM}$ of sodium pyruvate (WelGene), $55 \mu \mathrm{M}$ of $\beta$-mercaptoethanol (Life Technologies), and $1 \%$ antibiotics (100 U/ml penicillin and $100 \mu \mathrm{g} / \mathrm{ml}$ streptomycin; Life Technologies) at $37{ }^{\circ} \mathrm{C}$ in an atmosphere of $5 \% \mathrm{CO}_{2} . \mathrm{mpEF}$ cells $\left(1 \times 10^{6}\right.$ cells $\left./ \mathrm{ml}\right)$ were co-transfected with 4 ug of a pLNDT-2A5-Gal vector, which was linearized by a NotI restriction enzyme and purified by phenol:chloroform reagent, and $2 \mathrm{ug}$ of a pair of $\mathrm{ZFN}$ vectors using the Amaxa nuclofector system with U-023 program (Lonza, Basel, Switzerland) and seeded into 48-well plates. After $24 \mathrm{~h}$, transfected cells were selected by $300 \mu \mathrm{g} / \mathrm{ml}$ of neomycin reagent (Invitrogen) for 9 days and each of the single colonies were cultured. Genomic DNA was extracted from the candidate mpEF transfectants using a DNeasy extraction kit (Qiagen). PCR was performed using primer sets for transgenes (TG), $5^{\prime} \alpha$-Gal and/or $3^{\prime} \alpha$-Gal (Suppl. Table 2) and purified genomic DNAs as the template. PCR cycles were as follows: initial denaturation at $95{ }^{\circ} \mathrm{C}$ for $5 \mathrm{~min}$; 30 cycles of $94{ }^{\circ} \mathrm{C}$ for $30 \mathrm{~s}, 55^{\circ} \mathrm{C}$ (for TG), $65{ }^{\circ} \mathrm{C}$ (for $5^{\prime} \alpha$-Gal) or $50{ }^{\circ} \mathrm{C}$ (for $3^{\prime} \alpha$-Gal) for $30 \mathrm{~s}$, and $72{ }^{\circ} \mathrm{C}$ for $1 \mathrm{~min}$; followed by a final extension at $72{ }^{\circ} \mathrm{C}$ for $5 \mathrm{~min}$.

Production of reconstructed embryos and cloned piglets

Porcine ovaries were obtained from a local slaughterhouse (Nonghyup Moguchon, Gimje, Korea). Cumulus-oocyte complexes (COCs) were collected and washed in Tyrode's lactate-Hepes containing $0.1 \%$ $(\mathrm{w} / \mathrm{v})$ polyvinyl alcohol. Oocytes with several layers of cumulus cells were selected and washed three times in TCM-199 (GIBCO) supplemented with $0.1 \%$ polyvinyl alcohol (w/v), $3.05 \mathrm{mM}$ D-glucose, $0.91 \mathrm{mM}$ sodium pyruvate, $0.57 \mathrm{mM}$ cysteine, $0.5 \mu \mathrm{g} / \mathrm{ml}$ luteinizing hormone, $0.5 \mu \mathrm{g} / \mathrm{ml}$ follicle stimulating hormone, $10 \mathrm{ng} / \mathrm{ml}$ epidermal growth factor, $10 \%$ porcine follicular fluid (pFF), $75 \mu \mathrm{g} / \mathrm{ml}$ penicillin $\mathrm{G}$, and $50 \mu \mathrm{g} / \mathrm{ml}$ streptomycin (maturation medium). For in vitro maturation, $50 \mathrm{COCs}$ were transferred into $500 \mu \mathrm{L}$ of maturation medium in a four-well dish (Nunc, Roskilde, Denmark). The oocytes were matured for $40 \mathrm{~h}$ at $38.5{ }^{\circ} \mathrm{C}$ under $5 \%$ $\mathrm{CO}_{2}$ in air. Somatic cell nuclear transfer was performed as follows (Mezrich et al. 2003; Hauschild et al. 2011). Briefly, matured oocytes in manipulation medium supplemented with $5 \mu \mathrm{g} / \mathrm{ml}$ cytochalasin B were enucleated by aspirating the first polar body, metaphase II chromosomes, and a small amount of surrounding cytoplasm. The freshly-thawed donor cells treated with Roscovitine were inserted into the perivitelline space. The karyoplast-cytoplast complexes were placed into $0.2-\mathrm{mm}$ diameter wire electrodes (1 mm apart) of a fusion chamber covered with $0.3 \mathrm{M}$ mannitol solution containing $0.1 \mathrm{mM} \mathrm{MgSO}_{4}$, $1.0 \mathrm{mM} \mathrm{CaCl}_{2}$ and $0.5 \mathrm{mM}$ Hepes. For reconstruction, two DC pulses (1-s interval) of $1.5 \mathrm{kV} / \mathrm{cm}$ were applied for $30 \mu \mathrm{s}$ using an Electro-Cell fusion (Fujihira Industry, Tokyo, Japan). Immediately after the confirmation of fusion using a stereoscope, the reconstructed embryos were transferred into both oviducts of the surrogate on the same day or 1 day after the onset of estrus. Pregnancy was diagnosed on day 28 after embryo transfer and was checked regularly every week by ultrasound examination. The cloned piglets with multiple transgenes were delivered by natural parturition or Caesarean section.

Analysis of protein expression by western blotting

Total umbilical cord tissue extracts were harvested in RIPA buffer and then centrifuged at $12,000 \times g$ for 10 min at $4{ }^{\circ} \mathrm{C}$. Total protein was quantified using the BCA protein assay reagent, and then proteins were separated by SDS-PAGE and transferred to a PVDF membrane. After blocking in $5 \%$ milk in Trisbuffered saline containing Tween 20, the membrane was incubated with the specific primary antibody including human DAF (1:1000, \#GTX103951, GeneTex, Irvine, CA, USA), CD39 (1:1000, \#HPA014067, Sigma), TFPI (1:1000, \#HPA005575, Sigma), C1INH (1:1000, \#GTX105316, GeneTex), TNFAIP3 (1:1000, \#ab92324, Abcam, Cambridge, MA, USA), and $\beta$-actin (1:1000, \#4967, Cell signaling, Danvers, MA, USA), according to the manufacturer's recommendation. Signals were detected using ECL reagent according to the manufacturer's protocol. Densitometry analysis of the blotted membrane was performed using a LAS-3000 lumino image analyzer system (Fujifilm, Tokyo, Japan). 
Necropsy and histopathological analysis

The MGH GT ${ }^{-(\mathrm{DAF} / \mathrm{CD} 39 / \mathrm{TFPI} / \mathrm{C} 1-\mathrm{INH} / \mathrm{TNFAIP} 3) /+}$ piglets had normal suckling behaviors and vital signs, and did not show any birth defects after examination by veterinarians. Immediately after the death about $48 \mathrm{~h}$ after birth, the MGH transgenic piglets were necropsied to collect tissues and organs such as the brain, spleen, heart, liver, kidney, lung, stomach, testes, thymus, tongue, aorta, and adrenal gland, etc. The same tissues and organs were also collected from the 2-day-old non-transgenic littermates after being humanly euthanized. For the anesthesia and euthanization of control, it was injected with $20 \mathrm{mg} / \mathrm{kg}$ of Zoletil $^{\circledR} 50$ (Virbac, France) and $2.3 \mathrm{mg} / \mathrm{kg}$ of Rompun $^{\circledR}$ (Bayer, Toronto, Canada). Tissue samples from control and $\mathrm{GT}^{-(\mathrm{DAF} / \mathrm{CD} 39 / \mathrm{TFPI} / \mathrm{C} 1-\mathrm{INH} / \mathrm{TNFAIP} 3) /+}$ piglets were fixed in $10 \%$ buffered formalin, embedded in paraffin, and sectioned into $4-\mu \mathrm{m}$ slices. Sections were stained with hematoxylin and eosin (H\&E) and subjected to histopathological analysis. Blood was collected from the jugular vein of $\mathrm{GT}^{-(\mathrm{DAF} / \mathrm{CD} 39 / \mathrm{TFP} / \mathrm{C} 1-\mathrm{INH} / \mathrm{TNFAIP} 3) /+}$ and control piglets into tubes containing K2-EDTA (BD Vacutainer ${ }^{\circledR}$ ). Blood from the cloned littermates, but not targeted, was used as a control. Complete blood counting was performed using a haematology analyser Cell-Dyn ${ }^{\circledR}$ 3700 (Abbott Laboratories, Abbott Park, IL, USA) to determine the level of white blood cells (WBC), including the number of lymphocytes, monocytes, neutrophils, eosinophils, and basophils, as well as, red blood cells (RBC), platelets, haemoglobin, haematocrit, mean corpuscular volume, mean corpuscular haemoglobin concentration, and mean corpuscular haemoglobin.

\section{Immunohistochemistry}

Immunohistochemistry was carried out by the general procedures for paraffin-embedded section on the slides (Lee et al. 2006). For antigen retrieval, slides were placed in citrate buffer and heated in a microwave oven, then washed in dPBS. After treatment $0.3 \%$ Triton X-100 for $10 \mathrm{~min}$, sections were blocked in two steps; firstly, all sections were incubated with peroxidase blocking solution $\left(0.3 \% \mathrm{H}_{2} \mathrm{O}_{2}\right.$ in methanol) to block the endogenous peroxidase for $10 \mathrm{~min}$, and next, they were incubated with serum-free blocking solution (\#X0909, Dako, Denmark) for $1 \mathrm{~h}$. The same primary antibodies (dilution 1/100) that have been validated by western blot analysis were incubated overnight. After washing with $0.3 \%$ Tween 20 in $\mathrm{dPBS}$, the sections were incubated with HRP-conjugated anti-rabbit secondary antibody for $1 \mathrm{~h}$ (1:200, \#sc-2004, Santa Cruz, USA). The human proteins in pig tissues were visualized by using DAB (3,3'-Diamino-benzidine, \#K3468, Dako) as a substrate for $5 \mathrm{~min}$. Images of DAB stained tissue sections were captured under a light microscopy. Hematoxylin (\#CS700, Dako) was used for counter staining.

Statistical analysis

For statistical analysis, the GraphPad Prism 5.0 software package (GraphPad Software, La Jolla, CA, USA) was used. Data were analyzed by equal variance, two-tailed Student's $t$ test. $p$ values $<0.05$ were considered statistically significant.

\section{Results and discussions}

Establishment of pig cells expressing multiple human transgenes

During the first step to develop a transgenic piglet expressing multiple human genes to minimize graft rejection when transplanted in the primates, we constructed a polycistronic vector to express the following multiple human genes: hDAF, hCD39, hTFPI, hC1-INH, and TNFAIP3, in this order. Based on the findings that most acute vascular rejections are characterized by endothelial cell activation and cellular damage resulting in thrombotic microangiopathy, expression of human transgenes was constructed to be specific in the endothelium of the organ source piglets under the control of an ICAM2 promoter. Moreover, to deplete the $\alpha$-Gal antigen expression in the pig fibroblast cells, $5^{\prime}$ and $3^{\prime}$ fragments of exon 9 of the GT gene were added to both sides of the vector, respectively, to induce a chromosomal knock-in (KI) of the GT gene by homologous recombination (Fig. 1a). To verify the expression of each transgene by the $2 \mathrm{~A}$ system, RT-PCR was performed with cDNA prepared from porcine aortic endothelial cells (PAECs) transiently transfected with ICAM2-2A5 as the template and primers specific for each of the open reading frames of human transgenes (Fig. 1b). We established the KI transgenic fibroblast cell lines using the 
constructed vector. Established transgenic fibroblast cell lines were confirmed by genomic PCR on the junction region between $0.8 \mathrm{~kb}$ of promoter and $\mathrm{hDAF}$, and $1 \mathrm{~kb}$ of $5^{\prime}$ and $1.1 \mathrm{~kb}$ of $3^{\prime}$ exon 9 fragment of the GT gene using specific primer sets, respectively (Fig. 1c). The $\mathrm{GT}^{- \text {(DAF/CD39/TFPI/C1-INH/TNFAIP3)/+ }}$ piglet cell lines were cultured and completely characterized with the aforementioned methods and used in somatic cell nuclear transfer to re-clone the clones.

Generation of transgenic piglets

Individual productivities of cloned piglets were described in Table 1 . The pregnancy (7/15 vs. $3 / 4)$ and delivery (5/15 vs. $1 / 4)$ rates were comparable between cloning and re-cloning donor cells, respectively. Thirteen cloned piglets were born around days 114-117 of pregnancy by Caesarean section or natural parturition (Table 2). Five (cloning + recloning) out of 13 cloned piglets were confirmed as the $\mathrm{GT}^{-(\mathrm{DAF} / \mathrm{CD} 39 / \mathrm{TFPI} / \mathrm{C} 1-\mathrm{INH} / \mathrm{TNFAIP} 3) /+}$ piglets by genomic PCR with the above mentioned methods (Fig. 2a, b). In addition, our data shows some technological improvement in the cloning efficiency using MGH minipigs. The MGH minipig was established for organ transplantation studies across the reproducible homozygous major histocompatibility complex, called the swine leukocyte antigen (Sachs et al. 1976). Although reproductive characteristics of MGH minipigs are lower than those of domestic pigs (Conley et al. 1988; Mezrich et al. 2003) due to the inheritance of homozygous major histocompatibility complex in the highly inbred MGH minipigs, recipient-based cloning efficiency (no. of newborn piglets/transferred cloned embryos) of $\mathrm{GT}^{-(\mathrm{DAF} / \mathrm{CD} 39 / \mathrm{TFP} / \mathrm{C} 1-\mathrm{INH} / \mathrm{TNFAIP} 3) /+}$ cloned MGH piglets was highly increased to $5.33 \%$ in the present study when compared to the value of previous reports: $2.54 \%$ in $\mathrm{GT}^{-\mathrm{MCP} /+}$ (Hwang et al. 2013) and $0.2 \%$ in $\mathrm{GT}^{-/+}$cloned MGH minipigs (Hauschild et al. 2011).

Histopathological and hematological investigation

Behavior and milk consumption of the MGH $\mathrm{GT}^{-(\mathrm{DAF} / \mathrm{CD} 39 / \mathrm{TFPI} / \mathrm{C} 1-\mathrm{INH} / \mathrm{TNFAIP3}) /+}$ piglets were similar to previously generated piglets (Ahn et al. 2011; Kwon et al. 2011; Hwang et al. 2013). Gross observation at necropsy shows no significant pathological findings compared to non-transgenic littermates. Histological examination of organs, including the brain, spleen, heart, liver, kidney, lung, stomach, testes, thymus, tongue, aorta, and adrenal gland, did not show different pathological changes (data not shown). However, a complete blood count test of the MGH transgenic piglets showed significantly lower blood cell counts for WBCs $(p=0.001)$, including neutrophils $(p=0.035)$, lymphocytes $(p=0.008)$, eosinophils $(p=0.019)$, and basophils $(p=0.005)$, while no significant changes were observed in monocyte counts than those of non-transgenic littermates. Platelet counts $(p=0.008)$ were also significantly decreased in the transgenic piglets. On the other hand, RBC counts, hemoglobin, hematocrit, and mean corpuscular volume were not significantly changed, although a significant decrease in mean corpuscular hemoglobin $(p=0.017)$ was observed in the transgenic piglets (Table 3). These data suggest that transgenic expression of those human genes in pigs impairs hematopoiesis, but does not or minimally affects erythropoiesis.

Targeted transgenic protein expression was confirmed by western blot analysis using the umbilical cord of the $\mathrm{GT}^{- \text {(DAF/CD39/TFPI/C1-INH/TNFAIP3)/+ }}$ piglets (Fig. 2c). In addition, the protein expressions were

Table 1 Pregnancy and delivery rate by donor cell types

\begin{tabular}{lllll}
\hline Types & No. of embryos transferred & No. of surrogates & \\
\cline { 2 - 5 } & & Transferred & Pregnant $^{\mathrm{a}}$ & 7 \\
Cloning & $122 \pm 29$ & 15 & 3 & 5 \\
RE-cloning & $123 \pm 29$ & 4 & Delivered $^{\mathrm{b}}$ \\
\hline
\end{tabular}

Data were expressed as mean \pm standard deviation. Cloning: primary TG cell; RE-cloning: TG cells originated from cloning pig

${ }^{a}$ Pregnancy was confirmed by gestation sac formation using ultrasound examination at 28 days after embryo transfer

b No. of surrogates delivered/No. of surrogates pregnant 
Table 2 Full-term development of multi-transgenic cloned piglets

\begin{tabular}{|c|c|c|c|c|c|c|}
\hline \multirow[t]{2}{*}{ Types } & \multirow[t]{2}{*}{ No. of surrogates } & \multirow[t]{2}{*}{ Delivery status $^{\mathrm{a}}$} & \multicolumn{3}{|c|}{ No. of piglets born } & \multirow[t]{2}{*}{ Targeting } \\
\hline & & & Total & Survival & $\operatorname{Dead}^{\mathrm{b}}$ & \\
\hline \multirow[t]{5}{*}{ Cloning } & 1 & 117 (C-sec) & 4 & 2 & 2 & 1 \\
\hline & 2 & 117 (C-sec) & 1 & 1 & & - \\
\hline & 3 & 116 (natural) & 5 & 5 & & 2 \\
\hline & 4 & 117 (C-sec) & 1 & & 1 & - \\
\hline & 5 & $114(\mathrm{C}-\mathrm{sec})$ & 1 & 1 & & 1 \\
\hline Re-cloning & 6 & 114 (C-sec) & 1 & 1 & & 1 \\
\hline
\end{tabular}

Cloning: primary TG cell; Re-cloning: TG cells originated from cloning pig

All five targeted piglets died about $48 \mathrm{~h}$ after birth without specific symptoms

a Pregnancy periods after transfer of multi-transgenic cloned embryos

b Piglets that died within 1 day

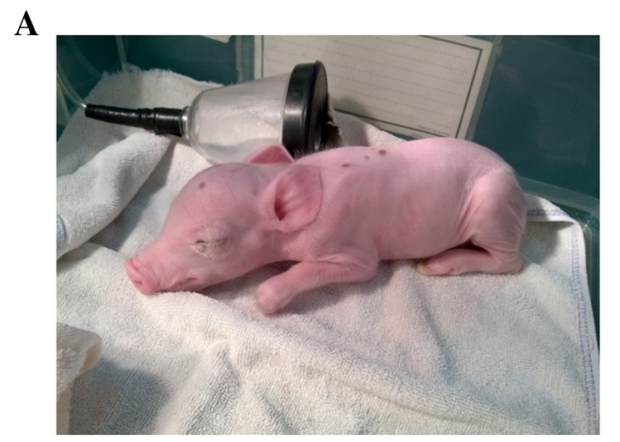

B

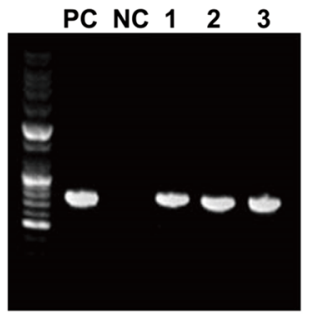

TG primer

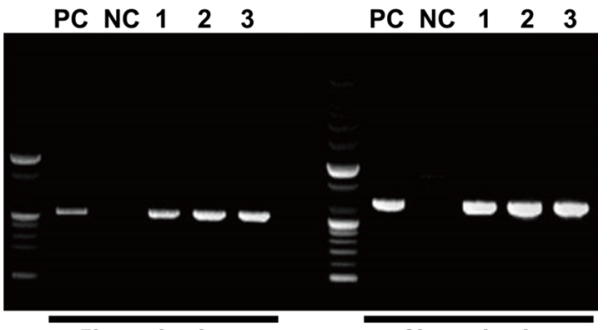

5' a-gal primer

3' a-gal primer

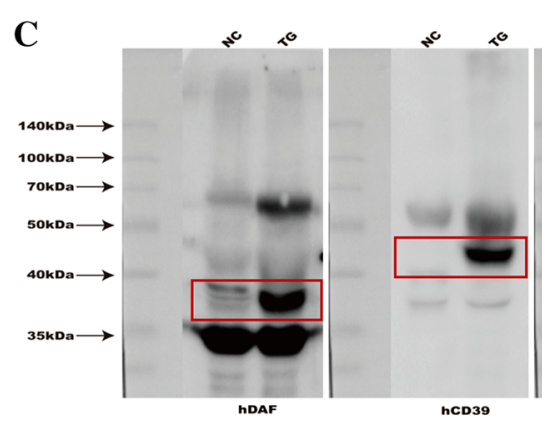

Fig. 2 Development of multiple gene expression pigs with GT knock-out. a The newborn GT ${ }^{-(D A F / C D 39 / T F P I / C 1-I N H / T N F A I P 3) /+~}$ Massachusetts General Hospital (MGH) piglet delivered by Caesarean section. b Genotyping of the piglets by RT-PCR. Three of the multiple transgenic piglets were confirmed genetically with the three primer sets. $P C$ positive control which is genomic DNA from cell line $\# 2$; $N C$ negative control

analyzed by immunohistochemical analysis. The hCD39, hTFPI, and hTNFAIP3 proteins were obviously detected in kidney, liver and aorta of the piglets, but not in those of the control wild-type piglet (Fig. S1). However, unlike western blot analysis,

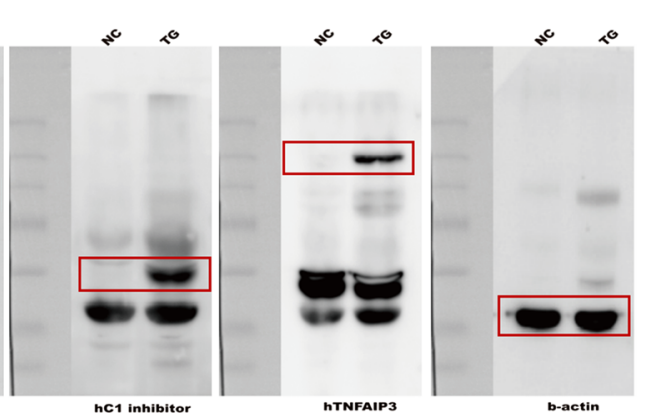

which is normal pig genomic DNA; 1, 2 and 3: genomic DNA from Knock-in pig \#1, 2, and 3. c western blot analysis. The knock-in piglets expressed the multiple human genes like the constructed vector. $N C$ negative control which is a normal pig; $T G$ a newborn $\mathrm{GT}^{-(\mathrm{DAF} / \mathrm{CD} 39 / \mathrm{TFPI} / \mathrm{C} 1-\mathrm{INH} / \mathrm{TNFAIP3}) /+}$ Massachusetts General Hospital (MGH) piglet. Red boxes represent the exact protein sizes

some of the tansgenic proteins, such as hDAF and hC1-INH, were not or weakly detected in those tissues, possibly due to low affinities of the antibodies on the tissue sections. Because all five human proteins were designed to be expressed as a single gene product 
Table 3 Mean values of hematological parameters in the newborn cloned piglets

\begin{tabular}{llccl}
\hline Abbreviation & Units & Reference $^{\mathrm{a}}$ & Multi-TG $(\mathrm{n}=2)^{\text {Control }^{\mathrm{b}}(\mathrm{n}=2)}$ \\
\hline WBC $(p=0.001)$ & $\times 10^{3} / \mu \mathrm{l}$ & $16.8-32.4$ & $1.3 \pm 0.66$ & $13.6 \pm 0.35$ \\
Neutrophils $(p=0.035)$ & $\times 10^{3} / \mu \mathrm{l}$ & $7.6-24.6$ & $0.14 \pm 0.01$ & $3.77 \pm 1.44$ \\
Lymphocytes $(p=0.008)$ & $\times 10^{3} / \mu \mathrm{l}$ & $3.42-12.7$ & $0.53 \pm 0.41$ & $7.65 \pm 1.21$ \\
Monocytes & $\times 10^{3} / \mu \mathrm{l}$ & $0.2-3.2$ & $0.58 \pm 0.25$ & $1.27 \pm 0.34$ \\
Eosinophils $(p=0.019)$ & $\times 10^{3} / \mu \mathrm{l}$ & $0.0-0.7$ & $0.03 \pm 0$ & $0.67 \pm 0.18$ \\
Basophils $(p=0.005)$ & $\times 10^{3} / \mu \mathrm{l}$ & $0.0-0.5$ & $0.03 \pm 0.004$ & $0.16 \pm 0.02$ \\
Platelet $(p=0.008)$ & $\times 10^{3} / \mu \mathrm{l}$ & $200-800$ & $74.9 \pm 27.9$ & $232 \pm 2.8$ \\
RBC & $\times 10^{3} / \mu \mathrm{l}$ & $6.4-9.3$ & $5.98 \pm 2.59$ & $7.38 \pm 1.1$ \\
Hemoglobin & $\mathrm{g} / \mathrm{dl}$ & $11.4-13.5$ & $10.19 \pm 4.4$ & $13.7 \pm 2.47$ \\
Hematocrit & $\%$ & $35-41$ & $34.95 \pm 15.5$ & $40.3 \pm 6.2$ \\
Mean corpuscular volume & $\mathrm{fl}$ & $48.1-63.9$ & $58.35 \pm 0.64$ & $54.7 \pm 0.35$ \\
Mean corpuscular hemoglobin & $\mathrm{pg}$ & $13.7-18.8$ & $17.0 \pm 0$ & $18.5 \pm 0.7$ \\
Mean corpuscular hemoglobin concentration & $\% / \mathrm{g} / \mathrm{dl}$ & $30.8-36$ & $29.2 \pm 0.28$ & $33.9 \pm 0.84$ \\
\hline
\end{tabular}

Two-tailed Student's $t$ test $(p<0.05)$

${ }^{a}$ Laboratory Animal Medicine 2nd edition, Edited by: Fox et al., Chapter 15-Biology and Diseases of Swine

b Control: non-transgenic cloned littermates

and subsequent western blot analysis of piglet tissues has confirmed that individual proteins are successfully produced by precise cleavage at the 'self-cleaving' $2 \mathrm{~A}$ peptide sequences, hDAF and hC1-INH proteins are certainly expressed in the transgenic piglets. This approach is practically advantageous in the transgenic expression of more than one protein from a single vector than the conventional approach, which requires the use of internal ribosome entry sequences or additional promoters, often leading to the differential expression level of proteins.

There have been previous reports demonstrating that transgenic expression of human DAF, CD39, TFPI, or TNFAI3 genes except C1-INH, alone or in combination, in pigs show no significant pathology in blood cells, such as leucopenia and thrombocytopenia. Moreover, the expression of C1-INH protein appears not to be directly correlated with leucopenia and thrombocytopenia because it plays a protective role against complement-mediated activation and subsequent cellular damages in endothelial cells (Dalmasso and Platt 1993; Fiane et al. 1999). In the current studies, the ectopic expression of all five transgenes in piglets, however, resulted in leucopenia and thrombocytopenia. Because blood leukocytes are the first line of defense against infection, and platelets play crucial roles to stop bleeding after blood vessel injuries, leucopenia and thrombocytopenia may be a major cause of the death of the transgenic piglets.

Among five transgenes, TFPI has been reported to promote platelet aggregation, leading to a remarkable decrease in platelet count (Nishioka et al. 2002; Ellery et al. 2015), which could partially explain the low platelet count in our transgenic piglets. Additional contributors to the decreased platelets in the pigs might be CD39 and DAF overexpression since transgenic production of human CD39 and DAF in mice resulted in slow clotting of human blood (Dwyer et al. 2006; Miwa et al. 2010).

Among the five target proteins that are consistently expressed in endothelial cells of the transgenic piglets, secretory proteins (TFP1 and C1-INH) that are circulating in the blood may systemically affect development of immune cells. Another possible explanation could be based on the finding that the human ICM2 promoter drove expression of transgene in endothelial cells and leukocytes, including neutrophils and monocytes (Cowan et al. 1996, 2003). Similar to the human promoter activities in the aforementioned transgenic mice, it is possible that the porcine ICAM2 promoter might be active in endothelial cells and leukocytes, but not in erythrocytes, consequently driving production of the five target proteins in both endothelial cells and leukocytes and affecting hematopoiesis in the transgenic piglets. 
Very recently, an abstract was reported that the survival of renal xenograft from a donor transgenic pig with 6 transgenes (GT KO/CD46/DAF/EPCR/TBM/ CD39) to baboon survived for 135 days (Ayares et al. 2015). The survival period of the 6-gene TG pig was shorter than the GT KO/CD55 transgenic pig ( $>227$ days). It is difficult to compare the survival results only in the survival period because of many different circumstances in both groups. Kidneys from GT KO/CD55/CD59/HTF pigs were transplanted into four baboons, and all of them were rejected within 10 days (Hawthorne et al. 2015).

Although organs from GT KO pigs with transgenic expression of multiple human genes involved in the immune and coagulation systems has resulted in an extended xenograft survival in primates (Le BasBernardet et al. 2011; Ayares et al. 2015; Hawthorne et al. 2015), much remains to be improved in generating multiple transgene expression in pigs for xenograft survivals, as the survival of xenografts is highly dependent upon many factors, including the kinds of transgenic genes, expression levels, and recipient and organ types.

Our current studies confront health issues of donor pigs with genetic modification of multiple genes that could bring beneficial aspects associated with immune suppression and anti-clotting of blood. Further studies are needed in both appropriate genetic modifications and immune responses in order to further extend survival.

\section{Conclusions}

In the present communication, we produced the transgenic piglets capable of simultaneously expressing five different human genes without $\alpha$-Gal antigen expression $\left[\mathrm{GT}^{-\left(\mathrm{DAF} / \mathrm{CD} 39 / \mathrm{TFPI} / \mathrm{C} 1-\mathrm{INH} / \mathrm{TNFAIP}^{2} /++\right.}\right]$. Accordingly, full understanding of the molecular mechanism involved in xenograft rejection, as well as the development of efficient technology to produce genetically manipulated organ-source piglets that harbor multiple human genes, are essentially required to improve the success rates of xenotransplantation in the future. However, several issues still remain to be resolved for clinical application of these strategies, including the selection of transgenes and potential pathological issues, such as leucopenia and thrombocytopenia, presented in this study. Better understanding of the biology and functional roles of candidate transgenes may help to develop safe and efficient approaches for the genetic manipulation of multi-TG pigs and for the successful xenotransplantation in the future.

Acknowledgments This work was carried out with the support of "Next Generation Biogreen 21 (Project No. PJ009095, PJ010956)" from the Rural Development Administration, Republic of Korea. This study was also supported by a Postdoctoral Fellowship Program of National Institute of Animal Science (Kwon DJ, Hwang IS), Rural Development Administration, Republic of Korea.

Author Contributions Seongsoo Hwang and Jeong-Woong Lee were responsible for the experimental design. Dae-Jin Kwon, Dong-Hwan Kim, In-Sul Hwang, Dong-Ern Kim, and Hyoung-Joo Kim performed experiments. Gi-Sun Im and JangSeong Kim planned and supervised the study. Seongsoo Hwang, Jeong-Woong Lee, and Kichoon Lee analyzed the data and wrote the manuscript. All authors read and approved the manuscript.

\section{Compliance with ethical standards}

Conflict of interest The authors declare no conflict of interest.

Open Access This article is distributed under the terms of the Creative Commons Attribution 4.0 International License (http:// creativecommons.org/licenses/by/4.0/), which permits unrestricted use, distribution, and reproduction in any medium, provided you give appropriate credit to the original author(s) and the source, provide a link to the Creative Commons license, and indicate if changes were made.

\section{References}

Ahn KS, Kim YJ, Kim M et al (2011) Resurrection of an alpha1,3-galactosyltransferase gene-targeted miniature pig by recloning using postmortem ear skin fibroblasts. Theriogenology 75:933-939

Ayares D, Vaught T, Ball S et al (2015) Six-gene multi-transgenic pigs serve as source animals to address innate and chronic rejection, inflammation, and coagulopathy in organ xenografts. In: Transplantation, pp s59-s59

Conley AJ, Jung YC, Schwartz NK et al (1988) Influence of SLA haplotype on ovulation rate and litter size in miniature pigs. J Reprod Fertil 82:595-601

Cowan PJ, Shinkel TA, Witort EJ et al (1996) Targeting gene expression to endothelial cells in transgenic mice using the human intercellular ahdesion molecule 2 promoter. Transplantation 62:155-160

Cowan PJ, Shinkel TA, Fisicaro N et al (2003) Targeting gene expression to endothelium in transgenic animals: a comparison of the human ICAM-2, PECAM-1 and endoglin promoters. Xenotransplantation 10:223-231 
Dalmasso AP, Platt JL (1993) Prevention of complement-mediated activation of xenogeneic endothelial cells in an in vitro model of xenograft hyperacute rejection by $\mathrm{C} 1$ inhibitor. Transplantation 56:1171-1176

Daniel S, Arvelo MB, Patel VI et al (2004) A20 protects endothelial cells from TNF-, Fas-, and NK-mediated cell death by inhibiting caspase 8 activation. Blood 104:2376-2384

Dwyer KM, Mysore TB, Crikis S et al (2006) The transgenic expression of human CD39 on murine islets inhibits clotting of human blood. Transplantation 82:428-432

Ellery PER, Maroney SA, Cooley BC et al (2015) A balance between TFPI and thrombin-mediated platelet activation is required for murine embryonic development. Blood 125:4078-4084

Fiane AE, Videm V, Johansen HT et al (1999) C1-inhibitor attenuates hyperacute rejection and inhibits complement, leukocyte and platelet activation in an ex vivo pig-to-human perfusion model. Immunopharmacology 42:231-243

Griesemer AD, Hirakata A, Shimizu A et al (2009) Results of gal-knockout porcine thymokidney xenografts. Am J Transplant 9:2669-2678

Hauschild J, Petersen B, Santiago Y et al (2011) Efficient generation of a biallelic knockout in pigs using zinc-finger nucleases. Proc Natl Acad Sci USA 108:12013-12017

Hawthorne W, Salvaris E, Hawkes J et al (2015) Enhanced survival of GalT KO/hCD55-hCD59 pig renal xenografts in baboons. In: Transplantation, pp S237-S237

Higginbotham L, Mathews D, Stephenson A et al (2015) Longterm survival of pig-to-primate renal xenotransplant using costimulation-blockade immunosuppression. In: Transplantation, pp s72-s73

Hwang S, Oh KB, Kwon D-J et al (2013) Improvement of cloning efficiency in minipigs using post-thawed donor cells treated with roscovitine. Mol Biotechnol 55:212-216

Kwon DJ, Kwak TU, Oh KB et al (2011) Effects of donor cell treatments on the production of transgenic cloned piglets. Reprod Dev Biol

Lai L (2002) Production of alpha-1,3-galactosyltransferase knockout pigs by nuclear transfer cloning. Science 295(80):1089-1092

Lambrigts D, Sachs DH, Cooper DK (1998) Discordant organ xenotransplantation in primates: world experience and current status. Transplantation 66:547-561
Le Bas-Bernardet S, Tillou X, Poirier N et al (2011) Xenotransplantation of galactosyl-transferase knockout, CD55, CD59, CD39, and fucosyl-transferase transgenic pig kidneys into baboons. Transplant Proc 43:3426-3430

Lee JW, Beebe K, Nangle La et al (2006) Editing-defective tRNA synthetase causes protein misfolding and neurodegeneration. Nature 443:50-55

Lee HJ, Lee BC, Kim YH et al (2011) Characterization of transgenic pigs that express human decay accelerating factor and cell membrane-tethered human tissue factor pathway inhibitor. Reprod Domest Anim 46:325-332

McGregor CG, Teotia SS, Byrne GW et al (2004) Cardiac xenotransplantation: progress toward the clinic. Transplantation 78:1569-1575

Mezrich JD, Haller GW, Arn JS et al (2003) Histocompatible miniature swine: an inbred large-animal model. Transplantation 75:904-907

Miwa Y, Yamamoto K, Onishi A et al (2010) Potential value of human thrombomodulin and DAF expression for coagulation control in pig-to-human xenotransplantation. Xenotransplantation 17:26-37

Mohiuddin M, Singh A, Corcoran P et al (2015) Critical need of continuous co-stimulation blockade with anti CD40 antibody (2C10. R4) for long-term maintenance of GTKO. HCD46. hTBM pig cardiac xenograft survival in baboons. In: Transplantation, pp S236-S236

Nishioka T, Yokota M, Hino M et al (2002) Tissue factor pathway inhibitor can interact with platelets. J Immunol Methods 266:181-184

Oropeza M, Petersen B, Carnwath JW et al (2009) Transgenic expression of the human A20 gene in cloned pigs provides protection against apoptotic and inflammatory stimuli. Xenotransplantation 16:522-534

Sachs DH, Leight G, Cone J et al (1976) Transplantation in miniature swine: i. Fixation of the major histocompatibility complex. Transplantation 22:559-567

Wheeler DG, Joseph ME, Mahamud SD et al (2012) Transgenic swine: expression of human CD39 protects against myocardial injury. J Mol Cell Cardiol 52:958-961

Yamada K, Yazawa K, Shimizu A et al (2005) Marked prolongation of porcine renal xenograft survival in baboons through the use of alpha1,3-galactosyltransferase geneknockout donors and the cotransplantation of vascularized thymic tissue. Nat Med 11:32-34 